\title{
EVIDENCE FROM THE FOSSIL RECORD OF AN ANTIPREDATORY EXAPTATION: CONCHIOLIN LAYERS IN CORBULID BIVALVES
}

\author{
GABRIELLE KARDON ${ }^{1}$ \\ Museum of Paleontology, University of Michigan, Ann Arbor, Michigan 48109-1079
}

\begin{abstract}
Conchiolin layers, organic-rich laminae, are characteristic of the shells of corbulid bivalves. The retention of these layers, despite their high metabolic cost, throughout the evolutionary history of Corbulidae has prompted the proposal of several adaptive scenarios to explain the origin and maintenance of these layers. The most widely held hypothesis contends that conchiolin layers are an adaptation for inhibiting drilling by predatory naticid gastropods. However, others suggest that the layers are adaptations to retard shell dissolution in waters undersaturated with calcium carbonate or to increase shell strength in the face of durophagous (shell crushing) predators. In this paper, experiments using recent Corbula (Varicorbula) gibba (Olivi) and observations of corbulids' present natural habitat demonstrate the current utility of conchiolin layers for all three functions: retardation of shell dissolution in waters undersaturated in calcium carbonate, increase of mechanical shell strength, and inhibition of drilling by predatory naticid gastropods. Earlier analyses of the extensive history of naticid predator-corbulid prey interactions suggested that conchiolin layers were an adaptation, a feature that promotes fitness and was built by selection for its current role, for deterring naticid predators. Not only are naticid drillholes widespread in fossil and recent corbulid shells, but an unusually large number of incomplete drillholes terminate unsuccessfully at conchiolin layers. In addition, a phylogenetic analysis of the origin of conchiolin layers and its function to deter naticid predators is consistent with a hypothesis of adaptation for this function. However, this hypothesis is rejected by an examination of fossil Jurassic Corbulomima. These oldest corbulids contained conchiolin layers before the evolution of naticid drilling during the Early Cretaceous. Therefore, conchiolin layers appear to be an exaptation, characters evolved for other usages and later "coopted" for their current role, for defense against drilling predators. The layers may in fact be an adaptation to resist durophagous predation.
\end{abstract}

Key words.-Adaptation, Corbulidae, functional morphology, Naticidae, predator-prey, shell.

Received September 23, 1996. Accepted September 12, 1997.

Conchiolin layers, organic-rich microstructural laminae, have arisen multiple times within the shells of ecologically distinct families of bivalves (Lewy and Samtleben 1979; Kat $1983,1985)$. The marine bivalve family Corbulidae has independently evolved conchiolin layers and the presence of the layers is characteristic (i.e., is a synapomorphy) of corbulids; most members of the family contain the layers (Lewy and Samtleben 1979; Kat 1985; Harper 1994) and the layers are not present in their sister group Myidae (nor their outgroup Hiatellidae; T. Waller, pers. comm. 1996). These layers, composed primarily of protein, have been retained throughout the evolutionary history of the Corbulidae despite the high metabolic cost of the protein fraction of the shell (Palmer 1983, 1992) and the repeated evolutionary tendency within the Gastropoda and Bivalvia toward loss of organic-rich microstructures from the shell (Taylor 1973; Carter 1980). Several adaptive scenarios have been advanced to explain the origin and maintenance of this metabolically expensive structure within corbulid shells.

Conchiolin layers are widely believed to be an adaptation that inhibits drilling by predatory naticid gastropods (Lewy and Samtleben 1979; Harper 1994). Using an accessory boring organ and radula to chemically dissolve and mechanically rasp the shell (reviewed by Carriker 1981), a naticid drills through the prey's shell and consumes the viscera. The resulting beveled drillhole provides a uniquely identifiable and preservable record (in both recent and fossil shells) of a successful predation event; an incomplete drillhole represents a failed predation event (Carriker and Yochelson 1968). For

\footnotetext{
${ }^{1}$ Present address: Department of Genetics, Harvard Medical School, Warren Albert Building, 200 Longwood Avenue, Boston, Massachusetts 02115; E-mail: gkardon@rascal.med.harvard.edu.
}

over a century, an anomalously high number of incomplete drillholes has been noted on recent and fossil corbulids as compared to other drilled bivalve species. Many (e.g., Jeffreys 1865; Lewy and Samtleben 1979; Harper 1994; but see Anderson et al. 1991; Fig. 1A) have assumed (or in a few cases demonstrated) that the incomplete drillholes terminated at conchiolin layers. In addition, complete naticid drillholes through corbulid shells often contain shelves (Fischer 1922; Hoffman et al. 1974; Robba and Ostinelli 1975; Lewy and Samtleben 1979; de Cauwer 1985; Fig. 1B), which, at least in Corbula gibba, are protruding conchiolin layers (Robba and Ostinelli 1975). These observations have led researchers to hypothesize that conchiolin layers are an adaptation for mechanically or chemically inhibiting drilling by predatory naticid gastropods.

Although the anti-naticid predation hypothesis has been widely accepted, alternative (potentially complementary) adaptational hypotheses for conchiolin layer function in corbulids have been proposed (Lewy and Samtleben 1979; Kat 1985; Harper 1994). Two of the more likely hypotheses are: (1) conchiolin layers retard shell dissolution by ambient waters undersaturated in calcium carbonate; and (2) conchiolin layers increase mechanical shell strength against durophagous (shell crushing) predators such as crabs and fish. Several researchers (Tevesz and Carter 1980; Isaji 1993, 1995) have provided evidence that conchiolin layers are deposited over the inner surface of the valves of distantly related freshwater and estuarine unionoidean and corbiculid bivalves as a physiological response to shell dissolution by water undersaturated in calcium carbonate. The layers also appear to decrease mortality (via invading microorganisms) from shell dissolution in freshwater streams (Kat 1982). The potential role of conchiolin layers for increasing the mechanical strength 

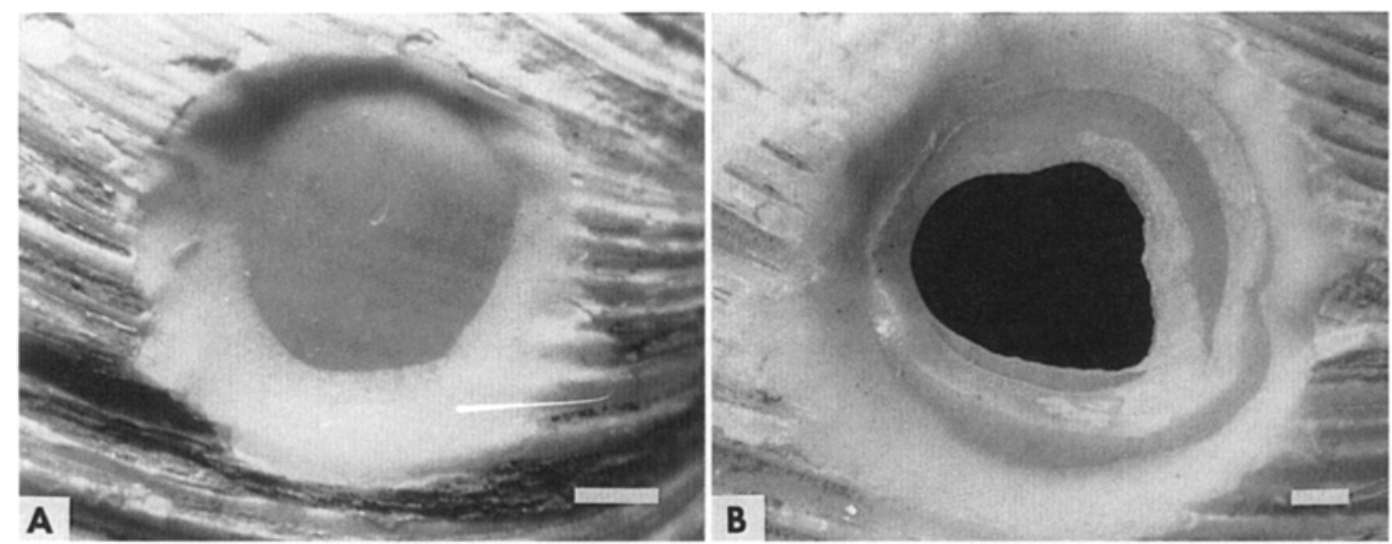

FIG. 1. Recent Neverita duplicatus drillholes through shells of Corbula gibba. (A) Incomplete drillhole that terminates at a conchiolin layer. (B) Complete drillhole with several shelves corresponding to protruding conchiolin layers. Scale bar $=0.5 \mathrm{~mm}$.

of corbulid shells has been suggested, although not tested by Kat (1985).

In this paper, I examine both the current utility and the adaptational history of conchiolin layers for the three proposed functions: retardation of shell dissolution, increase of mechanical shell strength, and inhibition of drilling by predatory naticid gastropods. Experimental tests of recent Corbula (Varicorbula) gibba determine whether the physical properties of the layers are sufficient to accomplish each of these functions. I also review the corbulids' present and historic natural environment to assess whether these functions are relevant to corbulid survival. By examining the presence of conchiolin layers in fossil Corbulidae from their first appearance through to the present and the prevalence of naticid predation in their historic natural environments, I explicitly test the most widely held hypothesis that conchiolin layers are an adaptation ("a feature that promotes fitness and was built by selection for its current role," Gould and Vrba 1982)

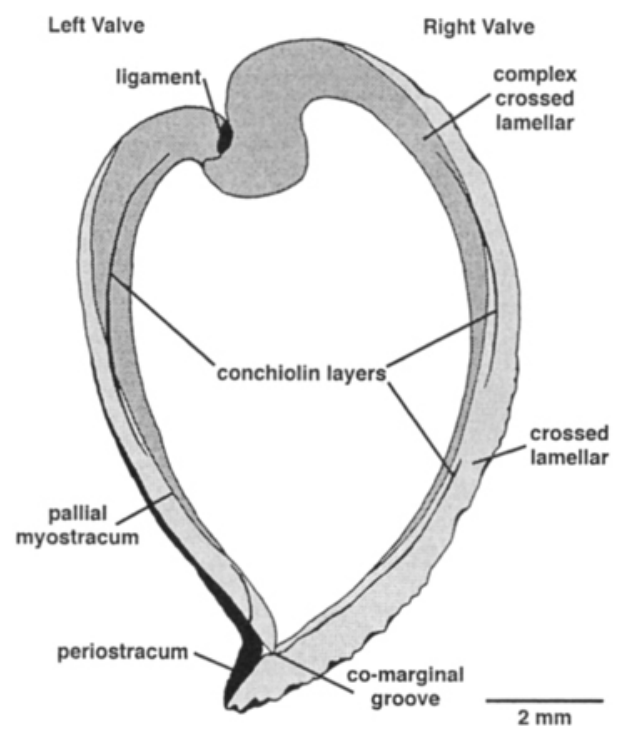

FIG. 2. Cross section through both valves of recent Corbula gibba showing microstructural units and position of conchiolin layers. The valves of $C$. gibba are highly unequal, with the right valves always larger. for inhibiting drilling naticid predators. Corbulid bivalves arose in the Jurassic, well before the evolution of naticid drilling in the Early Cretaceous. If Jurassic corbulids do contain conchiolin layers, the hypothesis that the layers are a specific adaptation for inhibiting drilling by naticid gastropods must be rejected.

\section{Materials and Methods \\ Corbulid Natural History}

Corbulidae first appeared in the fossil record with the genus Corbulomima in the Middle Jurassic, and the majority of corbulid genera diversified during the Cretaceous and Eocene (Vokes 1945; Hallam 1976; Lewy and Samtleben 1979). Both fossil and recent corbulids are found in temperate and tropical marine to brackish water (Lewy and Samtleben 1979). Living just beneath the sediment-water interface, they are slow-burrowing, generally sedentary, suspension feeders held in place by byssal threads (Yonge 1946; Stanley 1970; Morton 1986).

Corbula (Varicorbula) gibba (Olivi), obtained from the coast of Oban, Scotland, was chosen for the experiments because the species is long ranging (from the Miocene to the Recent) and geographically widespread (east Atlantic and Mediterranean).

\section{Corbulid Shell Morphology}

Corbulid shells characteristically contain within each valve at least one conchiolin layer that is accreted simultaneously with other microstructural layers (made of aragonite crystals and organic matrix) throughout most of the bivalve's life (Fig. 2). In the right valve of $C$. gibba the main conchiolin layer often, but not always, extends from the umbo, through the valve, and outcrops at the co-marginal groove in the shell interior (Lewy and Samtleben 1979; Morton 1986). The layer in the left valve also generally extends through the entire shell but outcrops at the ventral margin. Secondary layers were common in the adults of the $C$. gibba examined.

Microstructurally, the conchiolin layer of $C$. gibba consist of two regions: a homogeneous section consisting of finely laminated organic films and within this a reticulate section composed of chambers of conchiolin that contain "cones", of calcium carbonate (Lewy and Samtleben 1979; Kat 1985). 

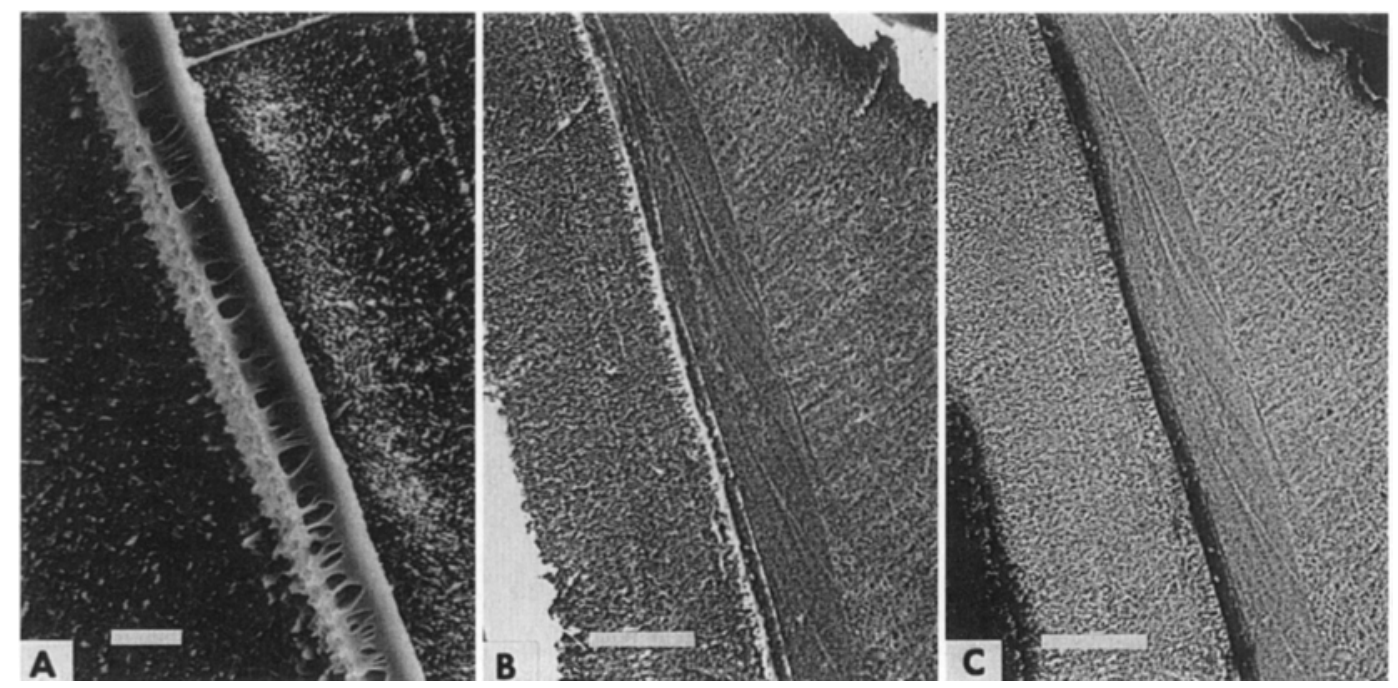

FIG. 3. SEM photomicrographs of recent and fossil conchiolin layers. The valve's exterior is to the right of each picture. (A) Closeup SSE image of recent Corbula gibba conchiolin layer. The layer's outer contact with the crossed lamellar aragonite is sharp and smooth, while the layer's lower surface is roughly reticulated. The homogeneous section lies toward the valve exterior, and the reticulate section lies beneath it. Calcium-carbonate cones, usually present in the reticulate section, were dissolved by the $\mathrm{HCl}$ etching. Scale bar $=10$ $\mu \mathrm{m}$. (B,C) Conchiolin layer of Eocene Vokesula smithvillensis, as seen under SSE (B) and BSE (C). Scale bars $=50 \mu \mathrm{m}$.

In most specimens, the two regions are clearly distinguishable with the scanning electron microscope (SEM) using secondary scattered electron (SSE) imaging (which reveals topographic relief). In addition, the sharp, smooth outer contact and the roughly reticulated inner contact of the conchiolin layer with the surrounding crossed lamellar unit are distinctive (Fig. 3A,B). Back-scattered electron (BSE) images (which reveal differences in material density) clearly show that the conchiolin layers are composed of organic material less dense than the surrounding calcium carbonate (Fig. 3C).

\section{Chemical Dissolution}

The ability of conchiolin layers to inhibit dissolution was tested by comparing the dissolution rate of $C$. gibba shells with that of bivalve Macoma balthica shells (collected on San Juan Island, Washington). Like the shells of $C$. gibba, $M$. balthica shells are composed of aragonite with an outer crossed lamellar layer and an inner complex crossed lamellar layer (Taylor et al. 1973). However, unlike C. gibba, M. balthica shells have no conchiolin layer and are thinner. From fresh shells without obvious degradation, blocks of roughly equal external surface area $(10 \times 7 \mathrm{~mm})$ were cut, leaving similar areas of the outer surface exposed on each block. Blocks were cut from freshly sacrificed $C$. gibba (three right and two left valves) and $M$. balthica (one right and one left valve). The outer surface of each shell was sanded to remove periostracum and ridges and produce surfaces of equal roughness. Nail polish was applied to all five faces except the external surface to ensure dissolution proceeded from only one direction.

Each specimen was placed in a nylon mesh bag that was suspended in a covered 1-L flask of $0.5 \%$ acetic acid undersaturated in calcium carbonate that was continually stirred and maintained at $27-32^{\circ} \mathrm{C}$. During all runs the solutions remained significantly undersaturated. Neither the nail polish nor nylon mesh bags were affected by the acetic acid.
One-ml samples were drawn from the acetic acid solutions at regular intervals, every $1-4 \mathrm{~h}$ from solutions containing C. gibba shells and every $15 \mathrm{~min}$ from solutions containing the thinner $M$. balthica shells. The samples were diluted with $40 \mathrm{ml}$ of distilled, deionized water, and the $\mathrm{Ca}^{2+}$ concentration in solution was measured on a flame ionization atomic absorption spectrophotometer. During sampling, the specimen was inspected for the presence of exposed conchiolin layers (visible as orange layers within the white aragonitic shell) and complete shell perforation.

\section{Mechanical Properties}

The mechanical properties of 12 valves $(9-13 \mathrm{~mm}$ in length; $0.68-0.95 \mathrm{~mm}$ in thickness) of recently sacrificed $C$. gibba were tested using a Monsanto tensometer equipped with a compression attachment. Intact, well-hydrated valves were carefully separated, placed in the tensometer with their commissural planes flush against the grip mount, and compressed between flat plates at a constant deformation rate. Load (the measured applied force) as a function of deformation (measured as the displacement of the tensometer plates) was recorded. The mechanical strength (defined here as the amount of force applied to a specimen at failure) under compression was also noted. Failure was defined as the point at which the specimen completely fractured. For comparison, six valves of $M$. balthica $(41-56 \mathrm{~mm} ; 0.44-0.58 \mathrm{~mm}$ in thickness) were subjected to the same tests. The fracture surface of compressed specimens was examined under the optical and scanning electron microscope.

\section{Drilling Naticid Gastropods}

The ability of conchiolin layers to deter naticid predation was investigated in two experiments on recent $C$. gibba: (1) drilling rate experiments measured the rate of penetration by naticids through corbulid shells to determine whether con- 
chiolin layers physically retard drilling; and (2) long-term observations of feeding behavior examined the effects of conchiolin layers on naticid predatory behavior. The historic effectiveness of conchiolin layers for deterring naticid predation was investigated using fossil corbulid assemblages.

\section{Drilling Rate}

Fourteen naticid Neverita duplicatus (individuals ranging from 19-35 $\mathrm{mm}$ in maximum length) and bivalve Mercenaria mercenaria $(10-30 \mathrm{~mm}$ in length) were collected from Woods Hole, Massachusetts. Corbula gibba (9-14 mm in length) were obtained from the coast of Oban, Scotland. Along the East Coast of the United States, M. mercenaria constitute a primary food source for $N$. duplicatus, but corbulids are rare. However, C. gibba commonly coexist with and are subject to predation by naticids on the Scottish coast. The experimental design, therefore, maximizes the likelihood of inhibition of naticid drilling by corbulid conchiolin layers, because $N$. duplicatus had no prior exposure to corbulids and would attack potentially fortified $C$. gibba.

Experiments were conducted in an aquarium with artificial sea water maintained at a temperature of $12-14^{\circ} \mathrm{C}$. The predators were housed in individual chambers filled with $2-3 \mathrm{~cm}$ of sand. All predators and prey were acclimated $10-30 \mathrm{~d}$ before experiments were begun, during which time the snails were fed two $C$. gibba.

After acclimation, snails were offered individual corbulids. After drilling was initiated, the predators were interrupted at known times, ranging from 17-38 h. Initiation time was set when the predator wrapped the prey in its mesopodium and the proboscis was seen in contact with the prey. Predators were alternately given prey and interrupted during drilling and then fed prey they were allowed to completely drill and consume.

Drilling rates through shell containing only aragonite and organic matrix were compared to rates through shell containing conchiolin layer(s), as well as aragonite and organic matrix. The effect of the conchiolin layers on drilling rate potentially can be isolated because the rate appears to be constant and does not vary with predator size (Kitchell et al. 1981).

The depth and number of conchiolin layers penetrated during drilling was determined by examining the interrupted, incomplete drillholes in cross-section. Drilled valves were embedded in plastic and two mutually orthogonal cuts made through the diameter and the deepest part of the drillhole. One of the perpendicular planes was polished, etched with $5 \% \mathrm{HCl}$ for five seconds, and examined on the SEM using SSE and BSE to assess the number of conchiolin layers penetrated (criteria for identifying layers are described below). Drillhole depths were measured directly off photomicrographs taken with SSE. On the photomicrograph, an outline of an arc of a circle was fitted across the outer rim of the drillhole to best approximate the curved, exterior surface of the shell material removed by drilling. The depth of the drillhole was measured as the distance, perpendicular to the fitted arc, from the arc to the deepest part of the hole. Deviations of the measured depths from true depths were assessed and corrected with measurements from the second perpendicular cut through the drillhole.

\section{Long-Term Feeding Observations}

Naticid predatory behavior was observed over nine months in which the 14 gastropods were fed a single $C$. gibba (9$14 \mathrm{~mm}$ in length) and occasionally a single $M$. mercenaria (10-30 $\mathrm{mm}$ in length) approximately every $2-4 \mathrm{wk}$, depending on the feeding rate of individual predators. For each predator, the number of incomplete and complete drillholes on C. gibba and M. mercenaria, number of incomplete drillholes terminating at conchiolin layers, number of complete drillholes with shelves (formed by prominent conchiolin layers) on corbulids, and number of shelves within these drillholes were noted. In incomplete drillholes, the number of shelves was an accurate indicator of the actual number of conchiolin layers (as determined by examining cross-sections with SEM) locally present.

\section{Historic Effectiveness of Conchiolin Layers}

The historic effectiveness of conchiolin layers for deterring naticid predation was investigated in fossil corbulid assemblages, using bulk samples collected from four localities along the U.S. Gulf Coast and Florida. From these bulk collections, samples of four species of corbulid bivalves were culled: Caestocorbula crassiplica from the Cretaceous Ripley Formation at Coon Creek, Tennessee; Notocorbula texana and Vokesula smithvillensis from the Eocene Stone City Formation at the Brazos River, Texas; and Varicorbula caloosae from the early Late Pliocene Pinecrest Beds in Sarasota, Florida, and the Late Pliocene Caloosahatchee Formation from the Miami Canal, Florida. For each of the bulk collections, the number of valves with complete and incomplete naticid drill holes was tallied. The presence of conchiolin layers at the termination of incomplete drillholes in five radially sectioned, well-preserved specimens was examined on the SEM (criteria for identifying conchiolin layers are described belów).

\section{Conchiolin Layers in Fossil Corbulids}

The presence of conchiolin layers in fossil corbulids was investigated using the same bulk samples (see previous section) collected from four Cretaceous to Pleistocene U.S. Gulf Coast and Florida localities. In addition, two articulated specimens of Corbulomima sp. from the Jurassic (Early Kimmeridgian) Lower Kimmeridge Clay Formation of Westbury, England, were examined.

Corbulid microstructure was surveyed by examining radial, etched $(5 \mathrm{~s}$ with $5 \% \mathrm{HCl}$ ) cross-sections of 5 valves of each species. Although the dark orange color of conchiolin layers renders them easily recognizable in recent corbulids, other criteria using SEM had to be developed for diagenetically altered fossils. Either (1) using BSE, the layer is composed of lighter elements or less dense material (indicative of organics versus surrounding calcium carbonate); or (2) using SSE, the layer of an etched specimen is clearly distinguishable (by virtue of topographic relief) as a thin, relatively continuous lamina.

Conchiolin layers occurring within the complex crossed 

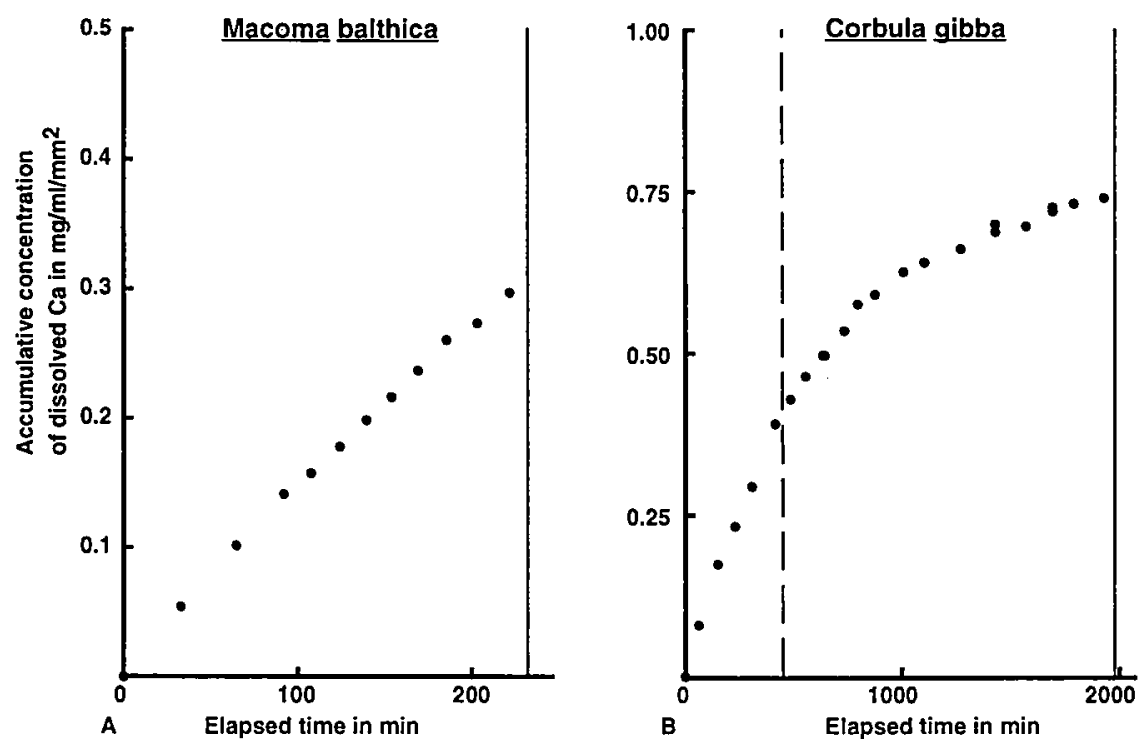

FIG. 4. Two representative plots of accumulated calcium dissolved by acetic acid, standardized by initial block surface area versus total elapsed time. (A) Dissolution of block of Macoma balthica shell. (B) Dissolution of block of Corbula gibba shell. Solid vertical lines demarcate times at which the specimens were completely perforated. The dashed line on the $C$. gibba plot demarcates the first visable exposure of conchiolin to the acetic acid. The scale of both axes of the two graphs differ. The scale of the calcium concentration axis differs because blocks of $M$. balthica were thinner than blocks of $C$. gibba, and therefore the overall amount of calcium dissolved from $M$. balthica shells was less than that dissolved from $C$. gibba shells. The scale of the time axis differs because the thinner $M$. balthica blocks were perforated more quickly, and therefore $M$. balthica samples were taken at shorter intervals than $C$. gibba samples (every 15 min vs. every $1-4 \mathrm{~h}$ ) to more accurately characterize calcium dissolution rate before block perforation.

lamellar microstructural unit, only identified by using SSE, may be confused with bands of prisms commonly found within this unit (Taylor et al. 1969). Any layers that could be confused with these bands of prisms were not included in
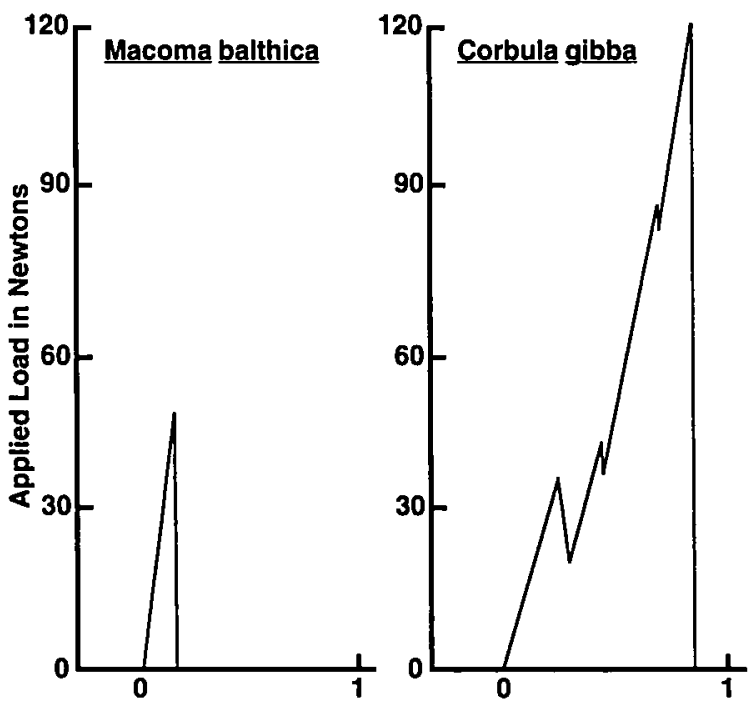

A Deformation in $\mathbf{m m}$

B Deformation in $\mathrm{mm}$

FIG. 5. Representative load-deformation curves of single valves compressed at a constant deformation rate. The measured applied force is plotted against the amount the specimen was deformed in the direction perpendicular to the commissural plane (measured as the displacement of the tensometer). (A) Curve for a valve of $\mathrm{Ma}$ coma balthica, $17.5 \mathrm{~mm}$ in length, $0.47 \mathrm{~mm}$ in thickness. Load increased monotonically until failure. (B) Curve for a valve of Corbula gibba, $13.3 \mathrm{~mm}$ in length, $0.72 \mathrm{~mm}$ in thickness. Load increased irregularly, with three abrupt decreases in load. my analysis. However, there were few of these ambiguous layers.

\section{RESULTS}

\section{Chemical Dissolution}

The experimental dissolution of $C$. gibba and $M$. balthica shells reveals that the conchiolin layers do inhibit the rate of shell dissolution in water undersaturated in calcium carbonate (Fig. 4A,B). Data from all $C$. gibba and $M$. balthica blocks dissolved show the same pattern, regardless of whether the blocks were cut from right or left valves. The relationship between dissolved [Ca] and time before block perforation differs between $C$. gibba and $M$. balthica (after perforation, dissolution rates decrease in response to the decreasing surface area available for reaction and so these values are ignored). The $M$. balthica relationship appears linear, while the C. gibba relationship appears curved. Interestingly, during the linear phase the $C$. gibba shell dissolves at a significantly slower rate than $M$. balthica (mean \pm SE: $0.879 \times 10^{-3} \pm$ $0.094 \times 10^{-3}$ vs. $1.37 \times 10^{-3} \pm 0.066 \times 10^{-3} \mathrm{mg} \mathrm{Ca} / \mathrm{min} /$ $\mathrm{mm}^{2}$; independent samples $t$-test, $t=4.63, P<0.0001, n=$ 36).

\section{Mechanical Properties}

The compression tests of $C$. gibba and $M$. balthica shells demonstrate that conchiolin layers increase the mechanical integrity of corbulid shells by acting as crack stoppers (Fig. $5 \mathrm{~A}, \mathrm{~B}$ ). Valves of C. gibba failed at compression loads of 50$126 \mathrm{~N}$. Right and left valves often differed in compressive strength by $20 \%$, although neither was consistently the stronger valve. Much larger $M$. balthica valves failed at forces of 


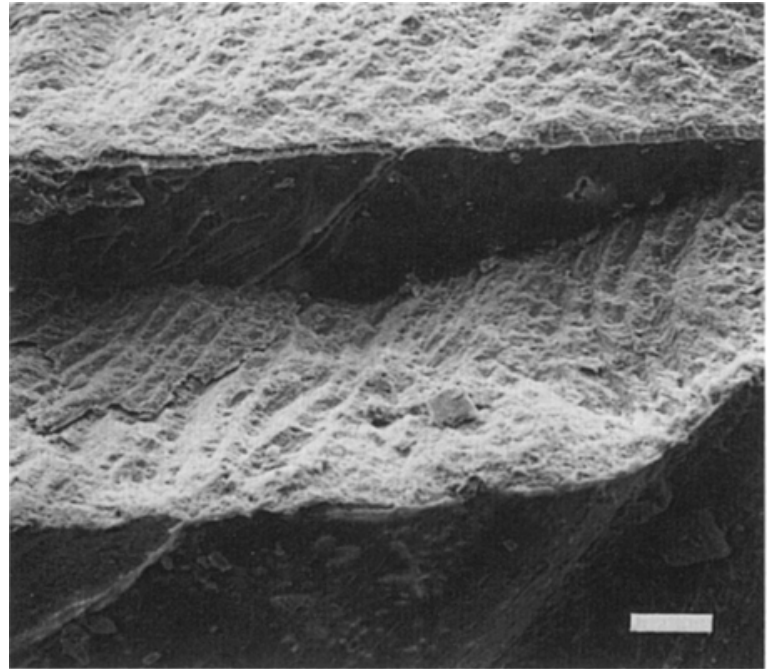

Fig. 6. Fracture surface of crushed Corbula gibba valve. The dark shelves of this stepped surface correspond to conchiolin layers. Scale bar $=50 \mu \mathrm{m}$.

only 40-50 N, but a large component of the superior strength of $C$. gibba is due to its shell thickness; $C$. gibba valves are twice as thick as an equivalently sized $M$. balthica.

More significant than the difference in absolute failure strength between $C$. gibba and $M$. balthica valves is the difference in the shape of the load-deformation curves between the two species. The load-deformation curve of all C. gibba shells tested has an unusual, but characteristic saw-tooth shape. Between one and three abrupt decreases in measured load were observed before failure of each compressed valve. Each drop in load appears to correlate with a crack originating on the interior, tensile shell surface that is subsequently blunted or deflected perpendicularly. The deflection of these cracks by conchiolin layers, and not by some other structure in the shell, is suggested by comparison of $C$. gibba and $M$. balthica load-deformation curves and by examination of fracture surfaces of failed $C$. gibba shells. The load-deformation curves of all tested $M$. balthica, which have a similar microstructure to $C$. gibba minus the conchiolin layers, never have a sawtooth shape, but instead show a monotonic increase until failure. SEM photomicrographs of fracture surfaces of failed C. gibba valves show numerous conchiolin layer shelves where cracks had been deflected perpendicular to their preferred paths, along the surface of conchiolin layers (Fig. 6).

\section{Inhibition of Drilling Naticid Gastropods}

Measurements of naticid drilling rates through conchiolin layers and aragonite suggest that conchiolin layers do not significantly retard drilling. However, behavioral observations of naticids feeding on corbulids reveal that the layers deter naticid predatory behavior, and this deterrence results in a large number of incomplete, unsuccessful drillholes. Examination of fossil corbulid assemblages provides evidence from temporally and spatially separated samples that conchiolin layers have been effective deterrents of naticid predation during the evolutionary history of this predator-prey interaction.

\section{Drilling Rate}

The mean drilling rate measured on $C$. gibba drillholes (Table 1 ) that did not penetrate any conchiolin layers $(0.0126$ $\mathrm{mm} / \mathrm{h} ; n=19$ ) was slightly slower than the drilling rate for drillholes that penetrated at least one conchiolin layer $(0.0142$ $\mathrm{mm} / \mathrm{h} ; n=10$ ); however, an independent samples $t$-test did not show significance $(t=1.45, P>0.15)$. A $t$-test on data from only right valve drillholes also did not detect any significant difference between drilling rates when conchiolin layers were penetrated and when they were not $(t=0.85, P$ $>0.40$ ). Interestingly, the drillhole with the slowest measured rate $(0.0076 \mathrm{~mm} / \mathrm{h})$ did not penetrate any conchiolin layers, while the hole which penetrated the most (three) layers had a higher than average drilling rate $(0.0138 \mathrm{~mm} / \mathrm{h})$. Differences in drilling rate could be obscured by variability among snails; however, an analysis of variance of drilling rates through no (or through $\geq 1$ ) conchiolin layers revealed no significant difference between mean drilling rates of individual predators $(F=0.91, P>0.50$ or $F=1.45, P>0.35$ ). In addition, the mean drilling rate of one predator (number 6) through no conchiolin layers or through one conchiolin layer was not significantly different $(t=0.50, P>0.50)$.

\section{Long-Term Feeding Observations}

During the nine-month observation period 13 of the 14 predators completely drilled and consumed $C$. gibba (Table 1). Most corbulids placed in the chambers were attacked by the naticid predators, but several predators took days or weeks to successfully drill prey. Twelve of the 92 attacked $C$. gibba contained only incomplete drillholes and effectively escaped naticid predation. In contrast, all $M$. mercenaria were completely drilled. Naticids were never observed to eat either prey without first completely drilling their shells (contra Medcof and Thurber 1958; Taylor et al. 1980) nor were they observed to drill dead or empty shells.

Forty percent of all predation attempts on $C$. gibba resulted in incomplete drillholes, while only $3 \%$ of predation attempts on $M$. mercenaria resulted in incomplete drillholes (Table 1). On either prey, naticids were never observed to reoccupy the incomplete drillholes (as also observed in Kitchell et al. 1981). An examination of the incomplete drillholes on corbulids ( $n=54)$ showed that 29 terminated at a conchiolin layer, and this is significantly more than expected ( $x^{2}$ goodness of fit, $\chi^{2}=148, P<0.005$ ). The expected value was calculated as the product of the number of incomplete drillholes (54) and the probability of a drillhole terminating at a conchiolin layer (assuming a constant drilling rate and random variation in time spent drilling); this probability was conservatively estimated as the largest proportion of shell thickness among all drilled valves found to be occupied by conchiolin layers. Despite abundant incomplete drillholes terminating at conchiolin layers, naticids often successfully penetrated these layers and completely drilled corbulids. Using the presence of shelves in the drillhole as a measure of the number of conchiolin layers penetrated, $71 \%$ of all the complete drillholes pierced at least one layer and $36 \%$ pierced at least two layers.

The individual predators differed greatly in the amount of difficulty they experienced while preying on $C$. gibba. For 
TABLE 1. Compilation of drilling rate data and feeding observations on 14 Neverita duplicatus predators and Corbula gibba and Mercenaria mercenaria prey.

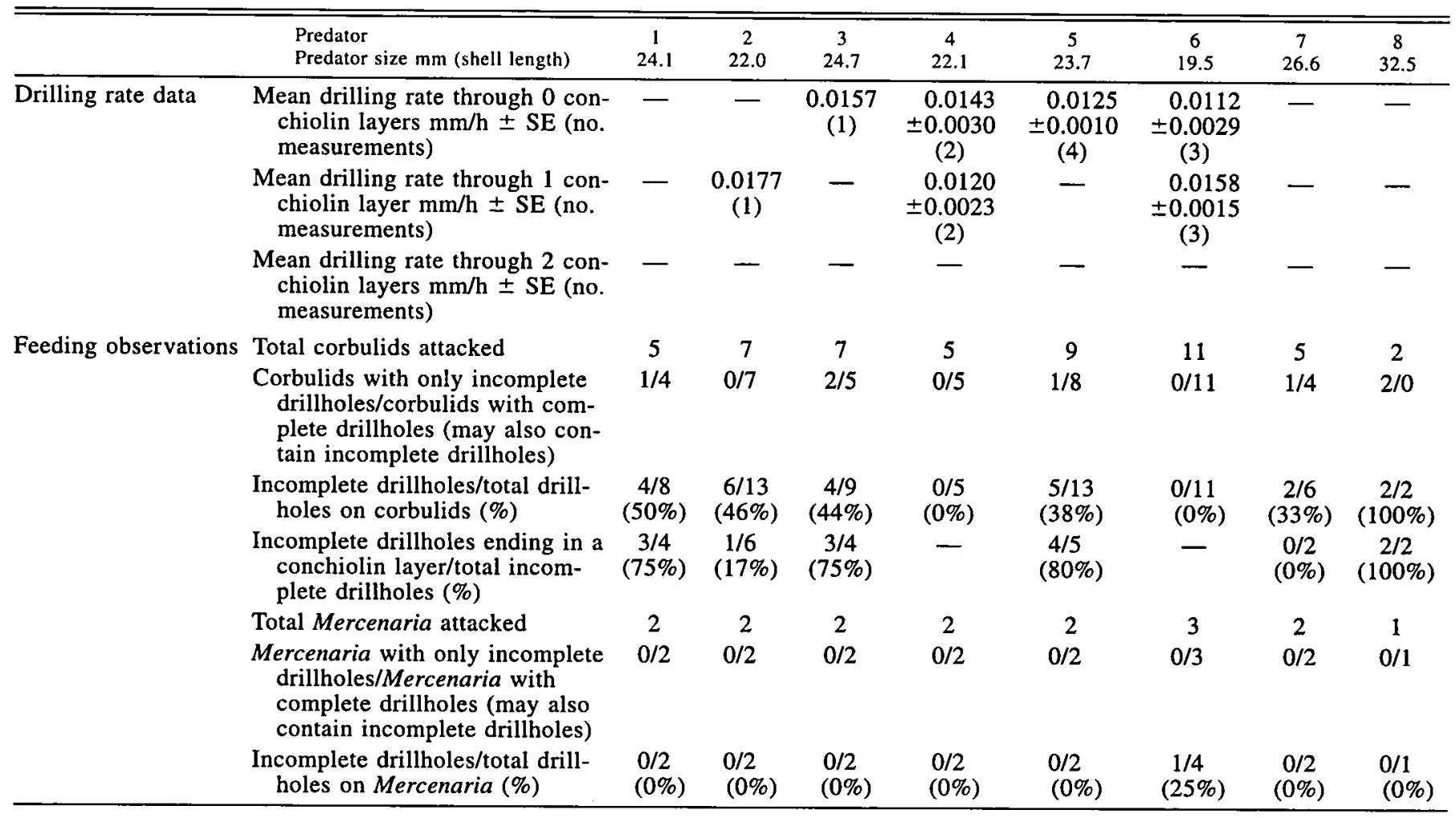

instance, two predators (numbers 4 and 6) completely drilled all of their prey on the first attempt, while another predator (number 13) consistently drilled multiple incomplete drillholes (up to four on one corbulid shell) before successfully drilling the prey. During the observation period, the naticids did not improve their predatory skills; individual predators experienced the same level of difficulty throughout the observation period.

\section{Historic Effectiveness of Conchiolin Layers}

Naticid predation intensity on corbulid bivalves (the percentage of valves drilled by naticids) in the four fossil assemblages ranged from $4 \%$ to $24 \%$ (Table 2 ). The frequency of unsuccessful drillholes varied from $0 \%$ to $22 \%$ in the assemblages and was highly variable between geographic localities and through geologic time. Examination of five incomplete drillholes in shells with well-preserved microstructure revealed that all drillholes terminated at a conchiolin layer.

\section{Conchiolin Layers in Fossil Corbulids}

Corbulids from all four bulk fossil assemblages contained conchiolin layers (Fig. 3B,C, Table 2). Generally each valve contained between one and four layers, though some lacked any layers. When present, the number and placement of conchiolin layers was highly variable within each corbulid assemblage; using all of the corbulid assemblages, no temporal trends in the data could be detected.

Both right and left valves of the two Jurassic Corbulomima specimens showed evidence of conchiolin layers (Fig. 7A). Although the valves had undergone some diagenesis, the original crossed lamellar microstructure and growth lines are clearly preserved. In the two right valves, traces of the conchiolin layer clearly outcropped at the co-marginal groove (Fig. 7A) in the pattern characteristic of all other corbulids (Fig. 7B). In the left valve, several continuous laminae continue from the beak, cross-cutting growth lines, toward the ventral margin.

\section{Discussion}

The experiments using recent $C$. (Varicorbula) gibba (Olivi) demonstrate that the physical properties of conchiolin layers are sufficient to accomplish three functions: (1) retard shell dissolution; (2) increase shell strength and toughness; and (3) deter naticid predatory behavior. In the following sections, I explore the relevance of these three functions to corbulid survival in the present day and historic past and evaluate the proposal that conchiolin layers are an adaptation to deter drilling naticid gastropods.

\section{Chemical Dissolution}

The experiments presented here demonstrate that conchiolin layers in Corbulidae retard shell dissolution in water undersaturated in calcium carbonate. This result agrees with the finding of Gabriel (1981) that shell microstructures containing a higher proportion of organics are more resistant to acid dissolution.

Bivalve shells are threatened by chemical dissolution pri- 
TABLE 1. Extended.

\begin{tabular}{ccccccc}
\hline \hline 9 & 10 & 11 & 12 & 13 & 14 & Total \\
24.8 & 23.7 & 20.9 & 32.6 & 27.3 & 34.5 & \\
\hline 0.0109 & 0.0128 & 0.0157 & - & - & 0.0137 & 0.0126 \\
\pm 0.0009 & $(1)$ & \pm 0.0003 & & & $(1)$ & $(19)$ \\
$(5)$ & & $(2)$ & & & & \\
- & - & 0.0142 & 0.0156 & - & 0.0103 & 0.0143 \\
& & $(1)$ & $(1)$ & & $(1)$ & $(9)$ \\
- & - & 0.0138 & - & - & - & 0.0138 \\
& & $(1)$ & & & & $(1)$ \\
7 & 6 & 9 & 8 & 7 & 4 & 92 \\
$0 / 7$ & $2 / 4$ & $0 / 9$ & $1 / 7$ & $2 / 5$ & $0 / 4$ & $12 / 80$ \\
& & & & & & \\
& & & & & & \\
$2 / 9$ & $5 / 9$ & $1 / 10$ & $8 / 15$ & $12 / 17$ & $3 / 7$ & $54 / 136$ \\
$(22 \%)$ & $(55 \%)$ & $(10 \%)$ & $(53 \%)$ & $(71 \%)$ & $(43 \%)$ & $(40 \%)$ \\
$2 / 2$ & $5 / 5$ & $1 / 1$ & $3 / 8$ & $4 / 12$ & $1 / 3$ & $29 / 54$ \\
$(100 \%)$ & $(100 \%)$ & $(100 \%)$ & $(38 \%)$ & $(33 \%)$ & $(33 \%)$ & $(54 \%)$ \\
3 & & & & & & \\
$0 / 3$ & $0 / 3$ & $0 / 4$ & $0 / 4$ & $0 / 3$ & $0 / 3$ & $0 / 36$ \\
& & & & & & \\
$0 / 3$ & $0 / 3$ & $0 / 4$ & $0 / 4$ & $0 / 3$ & $0 / 3$ & $1 / 37$ \\
$(0 \%)$ & $(0 \%)$ & $(0 \%)$ & $(0 \%)$ & $(0 \%)$ & $(0 \%)$ & $(3 \%)$ \\
\hline & & & & & &
\end{tabular}

marily in fresh water (well documented by Tevesz and Carter 1980; Kat 1982) or in the deep sea below the calcium carbonate compensation depth, where the water is undersaturated in calcium carbonate. Although some shallow, undersaturated, marine environments have been identified in which dissolution of living bivalves has been documented (Alexandersson 1976; Aller 1982; Reaves 1986; Isaji 1993, 1995), the shallow ocean is generally saturated with calcium carbonate and unlikely to cause shell dissolution (Thurman 1981).
Within this spectrum, corbulids are generally found in calcium carbonate saturated environments. Some recent and fossil corbulids have inhabited brackish water (Adams 1852; Keen 1971; Ryer 1977; Lewy and Samtleben 1979; Maslin 1989; Nuttall 1990; Anderson 1992), and at least one case of shell dissolution of living corbulids has been documented along the southeastern coast of England by Lewy and Samtleben (1979). However, from the Jurassic to the Recent, most members of Corbulidae have inhabited saturated shallow marine environments. Therefore, throughout their evolutionary history corbulid shells have not generally experienced dissolution.

For those corbulids that do suffer shell dissolution, dissolution is likely to be only an indirect source of mortality. A shell thinned by dissolution is weaker in the face of crushing and drilling predators, while a perforated shell exposes the soft parts to predators, invading microorganisms, and influxes of toxic or anoxic waters.

\section{Mechanical Properties}

The compression tests of $C$. gibba shells suggest that conchiolin layers increase shell strength and toughness by acting as crack stoppers (similar to the crack stopping properties of nacre and multiple layers of mutually perpendicular crossed lamellar aragonite shown by Currey and Kohn 1976; Currey 1977). During increasing compressive loading, numerous cracks are generated but fail to completely fracture the shell (reflected in the discontinous load-deformation curve, Fig. 5); only with sufficiently great loads will cracks completely break the shell. This suggests that shells without conchiolin layers would fail under stresses that would only incompletely crack shells with the layers. Conchiolin layers also increase the area of the fracture surface in crushed shells (Fig. 6). To produce this greater surface area, more work is required. Because the layers increase the work required for failure, they increase the overall toughness of the shell.

In the subtidal, muddy sand that corbulids inhabit, increased mechanical strength and toughness are important for resistance to durophagous predation by coexisting crusta-

TABLE 2. Survey of naticid predation on and presence of conchiolin layers in four species of Gulf Coast and Florida corbulids. Note that one Pliocene valve of $V$. caloosae contained both an incomplete and a complete drillhole, one valve of $N$. texana contained two incomplete drillholes, one valve of $N$. texana contained three incomplete drillholes, three valves of $N$. texana contained both an incomplete and a complete drillhole, one valve of $V$. smithvillensis contained two incomplete drillholes, and one valve of $V$. smithvillensis contained an incomplete and a complete drillhole.

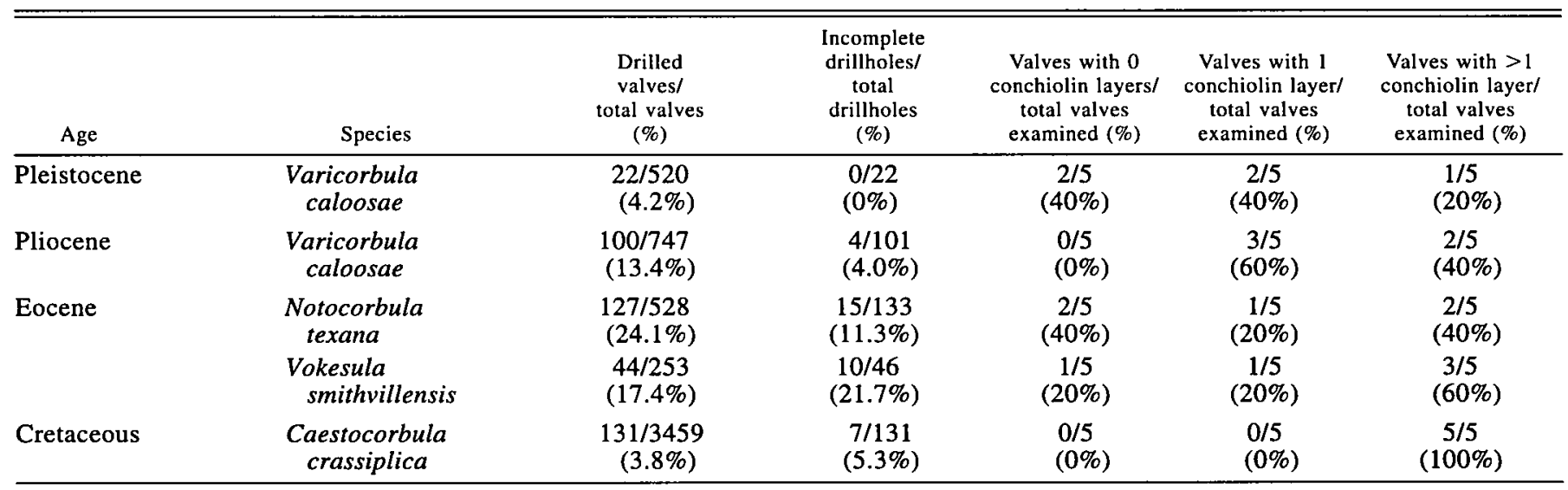




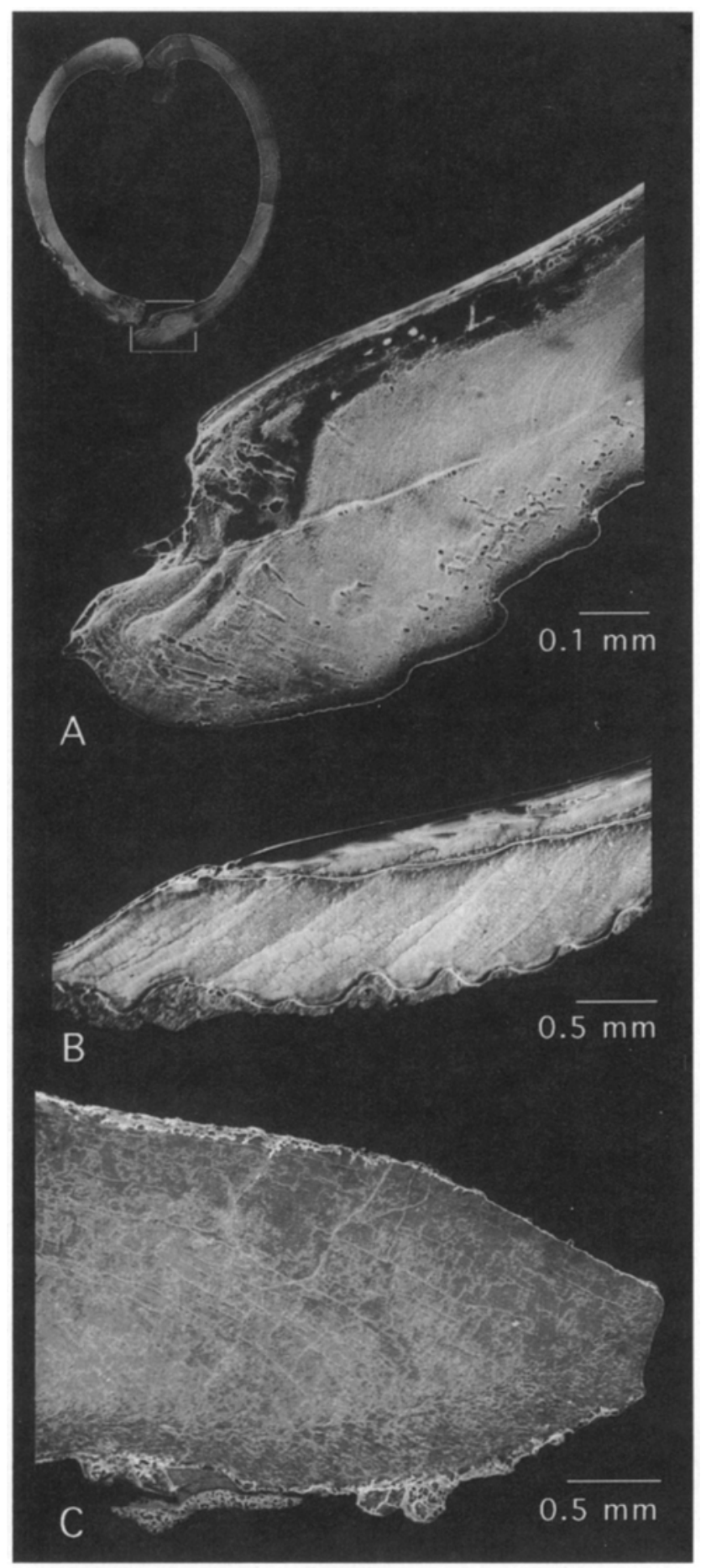

FIG. 7. SEM photomicrographs of Jurassic Corbulomima sp. (A), recent Corbula gibba (B), and Jurassic Jurassicorbula edwardi SMX 24505 (C). (A) Cross-section through both valves (composite of several photomicrographs) of Corbulomima and enlargement of right valve marginal region of Corbulomima. Although the valves have undergone some diagenesis, growth lines are clearly visible. The conchiolin layer stands out in topographic relief and clearly outcrops at a co-marginal groove. This conchiolin layer looks similar to that found in the right valve marginal region of C. gibba (B). (C) The left valve of $J$. edwardi has undergone significant diagenesis (only faint traces of growth lines are visible), and so the presence/ absence of conchiolin layers cannot be assessed. ceans and fish. Since corbulids are all small bivalves (less than $3 \mathrm{~cm}$ ) and contain a relatively large amount of biomass, they are attractive prey to all but the smallest durophagous predators. Their attachment to the substrate by byssal threads and small feet preclude rapid movement; consequently, the strength and toughness of their valves is more important than escape for resisting predation. Members of Corbulidae have probably been prey to durophagous crustaceans and fish since the Corbulidae's Middle Jurassic origin (Romer 1966; Schram 1982; Vermeij 1987). Evidence of resistance to attack (although not necessarily due to the crack-stopping abilities of conchiolin layers) is provided by predation scars such as those found on the Pliocene C. gibba (Robba and Ostinelli 1975 ) and Corbula vieta from the Miocene and early Pliocene of the northern Dominican Republic (Anderson 1992).

\section{Inhibition of Drilling Naticid Gastropods}

In experiments using $C$. gibba, no difference between the rate of naticid drilling through aragonitic shell alone and through aragonitic shell containing conchiolin layers was detected (Table 1). Differences in drilling rates may be obscured by two factors. The testing method is relatively insensitive; because the measured drilling rate through conchiolin layers also includes the rate through thick areas of aragonite, only large differences between the drilling rate through the relatively thin conchiolin layers and through aragonite can be detected. Variability of drilling rates among individual predators may also obscure differences in drilling rates. Although an analysis of variance did not detect differences in mean drilling rate among individual predators, the small samples sizes preclude a rigorous statistical analysis.

The observations of naticid feeding on corbulids reveal that conchiolin layers do deter naticid predatory behavior. The large number of complete drillholes containing shelves confirms that naticids often successfully drill through conchiolin layers. However, $40 \%$ of all predation attempts during feeding of the 14 predators were unsuccessful, despite the lack of $C$. gibba escape behavior. These unsuccessful attempts resulted in incomplete drillholes, of which an unexpectedly high number terminated at a conchiolin layer. If the conchiolin layers indeed do not slow the rate of drilling, these layers must stimulate some behavioral response in the naticids to stop drilling. This negative response to the conchiolin layers, however, was not universal (two of the 14 predators always drilled $C$. gibba successfully), but if present, it remained consistently throughout the feeding period.

The prevalence of naticid predation on corbulids is well documented by the large number of their distinctive drillholes on fossil and modern corbulid shells (Table 2; see data within de Cauwer 1985; Anderson 1994; Harper 1994; Hansen and Kelley 1995). There appears to be no overall temporal increase or decrease in the frequency of naticid attacks on corbulids (Table 2; de Cauwer 1985; Harper 1994) since the earliest naticid drillings in the Early Cretaceous (Taylor et al. 1983). However, variation in the frequency of drilling does not translate simply to variation in overall intensity of naticid predation on corbulids (see Fischer 1963; Taylor et al. 1983; de Cauwer 1985; Anderson 1992); variation in drilling frequency may only reflect local environmental differences in 
the number of naticid predators present and the range and abundance of prey available.

Much of this naticid predation has been unsuccessful, as recorded in the large number of incomplete drillholes in corbulids (Table 2; de Cauwer 1985; Harper 1994). In my samples, the conchiolin layers generally appear to have been lowlevel deterrents. However, Anderson (1992) has found that up to $76 \%$ of drillholes were incomplete in Corbula (Bothrocorbula) viminea in a Miocene Dominican Republic locality. Overall, the frequency of incomplete drillholes in corbulids does not appear to increase or decrease over time (Table 2; de Cauwer 1985; Harper 1994; but also see Kelley and Hansen 1993). However, my limited survey of incomplete drillholes revealed that all of these drillholes do terminate at conchiolin layers in the fossil assemblages examined. These data, in combination with data on both fossil and recent corbulids from Harper (1994) and Morton (1986), provide direct evidence that corbulid conchiolin layers do inhibit drilling naticid gastropods in the natural environment.

Drillhole-siting data on fossil corbulids (Culotta 1988) confirm my experimental data on recent naticids that the layers interfered with naticid predatory behavior. At least for $V$. caloosae from the Pinecrest Beds and Caloosahatchee Formation, drillhole siting on corbulids appears to be less stereotyped than that on most other prey species and indicates naticid difficulty in handling corbulids (Culotta 1988). Such unstereotyped drilling also has been recorded for corbulids from mid-Cretaceous to Miocene localities in the United States and Great Britain (Taylor et al. 1983; Kelley 1988; Kelley and Hansen 1993; Harper 1994; but also see Anderson et al. 1991; Anderson 1992).

\section{Conchiolin Layers in Fossil Corbulids}

All corbulid species examined from the Jurassic through the Recent appear to contain conchiolin layers. Harper's (1994) survey of Cretaceous to Recent corbulids also found that most corbulids contain conchiolin layers. Among specimens apparently lacking conchiolin layers, it is unclear whether the microstructure of these specimens is sufficiently well preserved to retain traces of the layers.

I found evidence of conchiolin layers in the oldest corbulids, Jurassic Corbulomima sp. (Fig. 7A). Although the preservation of these specimens was not as pristine as younger corbulids, continuous laminae cutting across growth layers were visible within the crossed lamellar aragonite and clearly outcropped at the co-marginal groove in right valves. Harper (1994) examined two specimens of Jurassic Jurassicorbula edwardi and concluded that, despite well-preserved microstructure, these early corbulids do not contain conchiolin layers. However, I have studied these same specimens (Fig. 7C) and find little evidence of original microstructure preserved and so find these specimens uninformative about the presence of conchiolin layers in Jurassic corbulids. Therefore, I conclude that the evidence from well-preserved fossil and recent corbulids indicates that conchiolin layers are characteristic of all members of Corbulidae from their Jurassic origin to the present day.

\section{Conchiolin Layers: an Exaptation for Inhibiting Drilling Naticid Predators}

Experimental results from this study demonstrate the current utility of conchiolin layers for retardation of shell dissolution in waters undersaturated in calcium carbonate, increase of mechanical shell strength, and inhibition of drilling by predatory naticid gastropods. In addition, the present occurrence of corbulids in calcium carbonate-undersaturated, ambient waters and coexistence with shell-crushing and drilling naticid predators suggest that conchiolin layers are adaptive for all three functions. Therefore, conchiolin layers certainly contribute to survivorship of present-day corbulids. However, these experimental results and observations of present-day corbulids do not address the origin of these adaptive functions.

The hypothesis that conchiolin layers are an adaptation against drilling naticid gastropods is testable in the fossil record. While the Corbulidae arose in the Jurassic, drilling by naticid gastropods did not become widespread until the Early Cretaceous. A few gastropod-like drillholes have been described from the Triassic (Fursich and Jablonski 1984), but despite extensive searches no record of gastropod drillholes has been found in Jurassic molluses (Sohl 1969; Fursich and Jablonski 1984). The first unequivocal naticid or muricid gastropod drillholes in either bivalves or gastropods do not appear until the Early Cretaceous Albian Blackdown Greensand of England (Taylor et al. 1983). The conchiolin layers in Jurassic Corbulomima demonstrates that conchiolin layers arose in corbulids before the appearance of drilling by naticid (or muricid) gastropods. Therefore, conchiolin layers are an exaptation, "characters evolved for other usages and later 'coopted' for their current role" (Gould and Vrba 1982), for deterring drilling naticids. The prevalence since the origin of the Corbulidae of durophagous crustaceans and fish and predation scars on corbulid shells suggest that conchiolin layers may in fact be an adaptation to resist durophagous predation.

\section{A Comment on Phylogenetic Tests of Adaptation}

In recent years, several authors (reviewed by Frumhoff and Reeve 1994; Larson and Losos 1996) have begun using reconstructed phylogenies to test hypotheses of adaptation, particularly in cases for which no historical data are available. However, this method may give misleading results without explicit historical data. Accurate mapping of changes in selective regimes via parsimony requires that the rate at which lineages move between selective regimes is low relative to the rate of lineage branching (Baum and Larson 1991) so that each shift in selective regime is demarcated by a branch. Yet this assumption may be violated if selective regimes change within lineages (Frumhoff and Reeve 1994). This study, with its explicit historical data, demonstrates not only an example of a violation of this assumption, but how this assumption may be misleading.

Without the historical data provided by the fossil record, a map on a corbulid phylogeny of the origin of conchiolin layers and their derived function to inhibit naticid drilling suggests that conchiolin layers are an adaptation for this function. My study and the work of Harper (1994) demonstrate that all examined well-preserved species of Corbulidae pos- 
sess conchiolin layers. Because the sister group Myidae and their outgroup Hiatellidae (T. Waller, per. comm. 1996; although earlier Morton [1986] questioned this relationship) do not have conchiolin layers, this trait must have arisen at the internode separating Myidae and Corbulidae. Without explicit temporal information, mapping the adaptive function for inhibiting drilling naticid gastropods on the phylogeny is more difficult. All genera of Corbulidae live in the subtidal sediments inhabited by naticids and probably have been subject to naticid predation. The abundance of corbulid shells containing incomplete drillholes terminating at conchiolin layers testify to the conchiolin layer inhibition of drilling naticids. Therefore, both the derived character state, presence of conchiolin layers, and their derived function, inhibition of naticid drilling, would be mapped at the same node between Myidae and Corbulidae. Because conchiolin layers are advantageous to corbulid survival, conchiolin layers would be determined to be adaptations for this function.

However, the data provided by the fossil record of corbulids and drilling by naticids demonstrates that conchiolin layers are not an adaptation for inhibiting drilling naticids. The presence of conchiolin layers in Jurassic and all subsequent corbulids suggests that conchiolin layers did arise at the internode between Myidae and Corbulidae or very early in the Corbulidae lineage. However, drilling by naticids became widespread in the Early Cretaceous, at least 50 million years after the origin of Corbulidae. In at least two genera, Corbula and Caestocorbula (and probably Corbulomima as well, see Moore 1969), the adaptive function or selective regime changes within the lineages. The fossil record reveals that the oldest members (older than Early Cretaceous) of these genera were not subject to drilling by naticid predators, however the more recent members (younger than Early Cretaceous) were. Therefore, the derived function of conchiolin layers needs to be mapped later than the origin of conchiolin layers on the Corbulidae lineage. The temporal data of the fossil record reject our initial hypothesis that conchiolin layers are an adaptation for inhibition of drilling by naticid gastropods.

Reconstructed phylogenies provide one method for testing hypotheses of adaptation. However, acceptance of a hypothesis of adaptation is contingent upon the assumptions of this method. As demonstrated here, the assumption that each shift in selective regime is demarcated by a branch can be violated. Only with explicit temporal data, such as that provided by the fossil record, can we discern when this assumption has been violated and, in certain cases, properly reject a hypothesis of adaptation.

\section{ACKNOWLEDGMENTS}

I thank E. E. Culotta for use of the Plio-Pleistocene, Florida assemblages she collected and P. Jeffery and N. Morris at the British Museum of Natural History for use of Jurassic Corbulomima. The two Jurassicorbula edwardi specimens were kindly loaned to me by the Sedgewick Museum, Cambridge. This paper has greatly benefited from the suggestions and technical assistance of L. C. Anderson, M. LaBarbera, D. E. Canfield, E. E. Culotta, and M. R. Johnston. D. C. Fisher, J. A. Kitchell, P. L. Koch, R. Mauricio, V. L. Roth, and $\mathrm{K}$. K. Smith read preliminary drafts and made many constructive suggestions. I also thank G. J. Vermeij and two anonymous reviewers for their comments. All specimens used in this paper are now held in the Museum of Paleontology, University of Michigan, Ann Arbor, except the specimens of Jurassic Corbulomima, which are held at the British Museum of Natural History, London. This project was funded by a Scott Turner Award and National Science Foundation grant BSR-8605310 to J. A. Kitchell.

\section{Literature Cited}

Adams, C. B. 1852. Catalogue of shells collected at Panama, with notes on their synonymy, station and geographical distribution. R. Craighead, New York.

AlEXANDERSSON, E. T. 1976. Actual and anticipated petrographic effects of carbonate undersaturation in shallow seawater. Nature 262:653-657.

AlLER, R. C. 1982. Carbonate dissolution in nearshore terrigenous muds: the role of physical and biological reworking. J. Geol. 90:79-95.

ANDERSON, L. C. 1992. Naticid gastropod predation on corbulid bivalves: effects of physical factors, morphological features, and statistical artifacts. Palaios 7:602-620.

- 1994. Paleoenvironmental control of species distributions and intraspecific variability in Neogene Corbulidae (Bivalvia: Myacea) of the Dominican Republic. J. Paleontol. 68:460-473.

Anderson, L.C., D. H. Geary, R. H. Nehm, and W. D. Allmon. 1991. A comparative study of naticid gastropod predation on Varicorbula caloosae and Chione cancellata, Plio-Pleistocene of Florida, U. S. A. Palaeogeogr. Paleoclimatol. Paleoecol. 85:2946.

BAUM, D. A., AND A. LARSON. 1991. Adaptation reviewed, a phylogenetic methodology for studying character macroevolution. Syst. Zool. 40:1-18.

CARRIKER, M. R. 1981 . Shell penetration and feeding by naticacean and muricacean predatory gastropods: a synthesis. Malacologia 20:403-522.

CARRIKer, M. R., AND E. L. Yochelson. 1968. Recent gastropod boreholes and Ordovician cylindrical borings. Contrib. Paleontol. USGS Prof. Pap. 593B:1-26.

CARTER, J. G. 1980. Environmental and biological controls of bivalve shell mineralogy and microstructure. Pp. 69-113 in D. C. Rhoads and R. A. Lutz, eds. Skeletal growth of aquatic organisms. Plenum Press, New York.

Culotta, E. 1988. Predators and available prey; naticid predation during a Neogene molluscan extinction event. Master's thesis, Univ. of Michigan, Ann Arbor.

CurReY, J. D. 1977. Mechanical properties of mother of pearl in tension. Proc. R. Soc. Lond. Ser. B Biol. Sci. 196:443-463.

CurRey, J. D., AND A. J. KoHN. 1976. Fracture in the crossedlamellar structure of Conus shells. J. Mater. Sci. 11:1615-1623.

DE CAUWER, G. 1985. Gastropod predation on corbulid bivalves: palaeoecology or taphonomy? Ann. Soc. R. Zool. Bel. 115:183196.

FISCHER, P. H. 1922. Sur les gasteropodes perceurs. J. Conchyiol. 67:1-56.

- 1963. Corbules fossiles perforees par des gasteropodes predateurs. J. Conchyiol. 103:29-31.

FrumhofF, P. C., AND H. K. ReEve. 1994. Using phylogenies to test hypotheses of adaptation: a critique of some current proposals. Evolution 48:172-180.

FURSICH, F T., AND D. JABLONSKI. 1984. Late Triassic naticid drillholes: carnivorous gastropods gain a major adaptation but fail to radiate. Science $24: 78-80$.

Gabriel, J. M. 1981. Differing resistance of various mollusc shell materials to simulated whelk attack. J. Zool. (Lond.) 194:363369.

Gould, S. J., AND E. S. VRBA. 1982. Exaptation-a missing term in the science of form. Paleobiology 8:4-15. 
Hallam, A. 1976. Stratigraphic distribution and ecology of European Jurassic bivalves. Lethaia 9:245-259.

HANSEN, T. A., AND P. H. Kelley. 1995. Spatial variation of naticid gastropod predation in the Eocene of North America. Palaios $10: 168-278$.

HARPER, E. M. 1994. Are conchiolin sheets in corbulid bivalves primarily defensive? Palaeontology 37:551-578.

Hoffman, A., A. Pisera, And M. Ryszkiewicz. 1974. Predation by muricid and naticid gastropods on the Lower Tortonian molluscks from the Korytnica clays. Acta Geol. Pol. 24:249-260.

ISAII, S. 1993. Formation of organic sheets in the inner shell layer of Geloina (Bivalvia: Corbiculidae): an adaptive response to shell dissolution. Veliger 36:166-173.

-1995. Defensive strategies against shell dissolution in bivalves inhabiting acidic environments: the case of Geloina (Corbiculidae) in mangrove swamps. Veliger 38:235-246.

JEFFREYS, J. G. 1865. British conchology. Vol. 3. John Van Voorst, London.

KAT, P. W. 1982. Shell dissolution as a significant cause of mortality for Corbicula fluminea (Bivalvia: Corbiculidae) inhabiting acidic waters. Malacol. Rev. 15:129-134.

. 1983. Conchiolin layers among the Unionidae and Margaritiferidae (Bivalvia): microstructural characteristics and taxonomic implications. Malacologia 24:298-311.

- 1985. Convergence in bivalve conchiolin layer microstructure. Malacol. Rev. 18:97-106.

KeEN, A. M. 1971. Sea shells of tropical west America. Stanford Univ. Press, Stanford, CA.

Kelley, P. H. 1988. Predation by Miocene gastropods of the Chesapeake group: stereotyped and predictable. Palaios 3:436-448.

Kelley, P. H., AND T. A. Hansen. 1993. Evolution of the naticid gastropod predatory-prey system: an evaluation of the hypothesis of escalation. Palaios 8:358-375.

Kitchell, J. A., C. H. BoGgs, J. F. Kitchell, AND J. A. Rice. 1981. Prey selection by naticid gastropods: experimental tests and application to the fossil record. Paleobiology 7:533-552.

LARSON, A., AND J. B. Losos. 1996. Phylogenetic systematics of adaptation. Pp. 187-220 in M. R. Rose and G. V. Lauder, ed. Adaptation. Academic Press, San Diego, CA.

Lewy, Z., And C. SAMTleben. 1979. Functional morphology and palaeontological significance of the conchiolin layers in corbulid pelecypods. Lethaia 12:341-351.

MASLIN, J. L. 1989. The salinity tolerance of Corbula trigona (Bivalvia: Corbulidae) from a West-African lagoon and its variations. Arch. Hydrobiol. 117:205-223.

MEDCOF, J. C., AND L. W. ThURBER. 1958. The control of the greater clam drill (Lunatia heros) by manual collection. J. Fish. Res. Bd. Can. 15:1355-1369.

MOORE, R. C., ED. 1969. Treatise on invertebrate paleontology. Vol. N. Mollusca Bivalvia. Univ. of Kansas, Lawrence.

MORTON, B. 1986. The biology and functional morphology of Corbula crassa (Bivalvia: Corbulidae) with special reference to shell structure and formation. Pp. 1055-1073 in Second international marine biological workshop: the marine flora and fauna of Hong Kong and southern China. Hong Kong.
Nuttall, C. P. 1990. A review of the Tertiary non-marine molluscan faunas of the Pebasian and other inland basins of northwestern South America. Bull. Br. Mus. (Nat. Hist.) Geol. 45: 165-371.

Palmer, A. R. 1983. Relative cost of producing skeletal organic matrix versus calcification: evidence from marine gastropods. Mar. Biol. 75:287-292.

1992. Calcification in marine molluscs: how costly is it? Proc. Nat. Acad. Sci. USA 89:1379-1382.

REAVEs, C. M. 1986. Organic matter metabolizability and calcium carbonate dissolution in nearshore marine muds. J. Sediment. Petrol. 56:486-494.

RobBa, E., ANd F. Ostinelli. 1975. Studi paleoecologi sul Pliocene Ligure. 1. Testimonianze di predazione sui molluschi Pliocenicic di Albenga. Riv. Ital. Paleontol. Stratigr. 81:309-372.

RoMER, A. S. 1966. Vertebrate paleontology, 3d ed. Univ. of Chicago Press, Chicago.

Ryer, T. A. 1977. Coalville and Rockport areas, Utah. Mount. Geol. 14:105-128.

SChram, R. F. 1982. The fossil record and evolution of Crustacea. Pp. 93-147 in L. G. Abele, eds. The biology of Crustacea. Academic Press, New York.

SoHL, N. 1969. The fossil record of shell boring by snails. Am. Zool. 9:725-734.

STANLEY, S. M. 1970. Relation of shell form to life habitats in the Bivalvia (Mollusca). Geological Society of America Memoir no. 125.

TAYLOR, J. D. 1973. The structural evolution of the bivalve shell. Paleontology 16:519-534.

TAylor, J. D., W. J. Kennedy, and A. Hall. 1969. The shell structure and mineralogy of the Bivalvia. Introduction. Nuculacea-Trigonacea. Bull. Br. Mus. (Nat. Hist.) Zool. Suppl. 3:1125 .

. 1973. The shell structure and mineralogy of the Bivalvia. II. Lucinacea-Clavagellacea. Conclusions. Bull. Br. Mus. (Nat Hist.) Zool. 22:255-294.

TAYlOR, J. D., N. J. Morris, AND C. N. TAYlor. 1980. Food specialization and the evolution of predatory prosobranch gastropods. Palaeontology 23:375-409.

Taylor, J. D., R. J. Cleevely, And N. J. Morris. 1983. Predatory gastropods and their activities in the Blackdown Greensand (Albian) of England. Palaeontology 26:521-553.

Tevesz, M. J. S., AND J. G. CARTER. 1980. Environmental relationships of shell form and structure of unionacean bivalves. $\mathrm{Pp}$. 295-322 in D. C. Rhoads and R. A. Lutz, eds. Skeletal growth of aquatic organisms. Plenum Press, New York.

Thurman, H. V. 1981. Introductory Oceanography. 3d ed. Merrill Publishing, Columbus, OH.

VERMEIJ, G. J. 1987. Evolution and escalation: an ecological history of life. Princeton Univ. Press, Princeton, NJ.

VoKEs, H. W. 1945. Supraspecific groups of the pelecypod family Corbulidae. Bull. Am. Mus. Nat. Hist. 86:1-32.

Yonge, C. M. 1946. On the habits and adaptation of Aloidis (Corbula) gibba. J. Mar. Biol. Assoc. U.K. 26:358-36.

Corresponding Editor: A. Palmer 